\title{
Cardiomyocyte microvesicles: proinflammatory mediators after myocardial ischemia?
}

\author{
Patrick Malcolm Siegel ${ }^{1,2}$ - Judith Schmich ${ }^{1,2}$. Georg Barinov ${ }^{1} \cdot$ István Bojti ${ }^{1}$. Christopher Vedecnik ${ }^{1}$. \\ Novita Riani Simanjuntak ${ }^{1}$. Christoph Bode ${ }^{1} \cdot$ Martin Moser $^{1} \cdot$ Karlheinz Peter $^{2,3} \cdot$ Philipp Diehl $^{1,2,3}$
}

Published online: 14 June 2020

(c) The Author(s) 2020, corrected publication, 2021

\begin{abstract}
Myocardial infarction is a frequent complication of cardiovascular disease leading to high morbidity and mortality worldwide. Elevated C-reactive protein (CRP) levels after myocardial infarction are associated with heart failure and poor prognosis. Cardiomyocyte microvesicles (CMV) are released during hypoxic conditions and can act as mediators of intercellular communication. MicroRNA (miRNA) are short non-coding RNA which can alter cellular mRNA-translation. Microvesicles (MV) have been shown to contain distinct patterns of miRNA from their parent cells which can affect protein expression in target cells. We hypothesized that miRNA containing CMV mediate hepatic CRP expression after cardiomyocyte hypoxia. H9c2cells were cultured and murine cardiomyocytes were isolated from whole murine hearts. H9c2- and murine cardiomyocytes were exposed to hypoxic conditions using a hypoxia chamber. Microvesicles were isolated by differential centrifugation and analysed by flow cytometry. Next-generation-sequencing was performed to determine the miRNA-expression profile in H9c2 CMV compared to their parent cells. Microvesicles were incubated with a co-culture model of the liver consisting of THP-1 macrophages and HepG2 cells. IL-6 and CRP expression in the co-culture was assessed by qPCR and ELISA. CMV contain a distinct pattern of miRNA compared to their parent cells including many inflammation-related miRNA. CMV induced IL-6 expression in THP-1 macrophages alone and CRP expression in the hepatic co-culture model. MV from hypoxic cardiomyocytes can mediate CRP expression in a hepatic co-culture model. Further studies will have to show whether these effects are reproducible in-vivo.
\end{abstract}

Keywords C-reactive protein $\cdot$ Myocardial infarction $\cdot$ Microvesicles $\cdot$ Cardiomyocytes

\section{Highlights}

- Microvesicle release from cardiomyocytes is increased during hypoxia

Karlheinz Peter and Philipp Diehl have contributed equally.

Patrick Malcolm Siegel

patrick.siegel@universitaets-herzzentrum.de

1 Cardiology and Angiology I, Heart Center Freiburg University, Medical Faculty, University of Freiburg, 79106 Freiburg im Breisgau, Germany

2 Baker Heart \& Diabetes Institute, Atherothrombosis \& Vascular Biology Laboratory, Melbourne, Australia

3 Faculty for Medicine \& Nursing, Monash University, Melbourne, Australia
- Cardiomyocyte microvesicles contain a distinct set of miRNA from their parent cells

- CMV contain inflammation associated miRNA

- CMV stimulate IL-6 expression in THP-1 macrophages

- CMV stimulate CRP expression in a hepatic co-culture model

\section{Introduction}

Cardiovascular disease and myocardial infarction in particular, are the leading cause of mortality worldwide [1]. Inflammation plays a major role in the immune response after myocardial infarction [2]. Elevated serum-CRP-levels after myocardial infarction are associated with "harmful inflammation" and poor outcomes [3, 4]. As a part of the acute phase response [5], CRP is produced by hepatocytes following stimulation by IL-6 from Kupffer cell macrophages 
lining the liver sinusoids [6, 7]. Elevated IL-6 levels have been reported after myocardial infarction [8]. However, the exact mechanisms leading to an increase in IL- 6 and CRP after myocardial infarction have not been sufficiently characterised.

Microvesicles (MV) are small membrane vesicles released by most cell types upon activation and apoptosis. They are loaded with bioactive molecules including proteins, mRNA, microRNA which are distinct from their parent cells and can alter the function of their target cells rendering them intercellular mediators [9-11].

Cardiomyocyte microvesicles (CMV) are released under stress during myocardial infarction or hypoxia $[12,13]$. They have been shown to contain proinflammatory cytokines such as TNF- $\alpha$ [14], DNA, mRNA [15] and various miRNA [16] which they protect from degradation. Multiple functions have been attributed to CMV, for example delivery of distinct miRNA [13] to fibroblasts or monocytes after myocardial infarction and protection of the heart from ischemia reperfusion injury [17].

In the following, we would like to suggest a theory of how CMV may lead to increased hepatic CRP production after myocardial infarction. It is intended to explain to the reader why we performed the in-vitro studies described in the results section: After myocardial infarction (Fig. 1a) hypoxic cardiomyocytes release $\mathrm{CMV}$ into the circulation (Fig. 1b) which are loaded with a distinct set of pro-inflammatory mediators including miRNA. After reaching the hepatic circulation CMV are first taken up by Kupffer cells (specialized macrophages in the liver) lining the walls of the sinusoids (Fig. 1c). There, they promote IL-6 expression which, in a paracrine manner, then induces CRP expression in hepatocytes (Fig. 1d).

The aim of this study was to investigate the effects of CMV from hypoxic cultured cardiomyocytes on hepatic CRP expression.

\section{Materials and methods}

\section{Cell culture and stimulation}

THP-1 cells, HUVEC and H9c2 (immortalized rat myoblasts [18]) (ATCC, USA) and HepG2 (immortalized hepatocytes, CellBank, Australia) were cultured using standard protocols.

Before stimulation, cells were seeded in 6-well plates and incubated for $72 \mathrm{~h}$. THP- 1 cells were differentiated into macrophages using PMA $(200 \mathrm{ng} / \mathrm{mL})$. Cells were stimulated with isolated CMV or PBS for different durations followed by RNA-extraction and qRT-PCR. THP-1 cells were also stimulated with LPS $(15 \mu \mathrm{g} / \mathrm{mL})$ as a positive control.

\section{Co-culture of HepG2 and THP-1 cells and stimulation}

We created a simplified model of the liver by co-culturing THP-1 macrophages and HepG2 liver cells. THP-1 cells were differentiated to macrophages and washed before HepG2 cells were added. After incubation for $72 \mathrm{~h}$, co-cultures were stimulated with CMV, LPS $(15 \mu \mathrm{g} / \mathrm{mL})$, PBS or medium followed by RNA-extraction and qRT-PCR.

\section{Isolation of murine cardiomyocytes}

Isolation of murine cardiomyocytes was performed as described elsewhere [19]. Briefly, male C57BL/6 mice were euthanized, the heart was surgically removed and connected to a Langendorff perfusion system followed by perfusion with a collagenase solution for up to $50 \mathrm{~min}$. The heart was transferred into petri-dishes, the atria were removed, and undigested parts of the heart muscle were eliminated using a filter. Isolated cardiomyocytes were then cultured in laminincoated (Sigma-Aldrich, USA) dishes using minimal essential medium (MEM, Gibco ${ }^{\circledR}$, USA) supplemented with $2.5 \%$ FBS and $50 \mathrm{U} / \mathrm{mL}$ penicillin and $50 \mu \mathrm{g} / \mathrm{mL}$ streptomycin.

\section{Measurement of troponin-T}

Troponin-T was quantified using the Cobas 8000 Modular Analyser (Roche, Switzerland).

\section{Isolation of CMV after cardiomyocyte hypoxia}

$7 \times 10^{5} \mathrm{H} 9 \mathrm{c} 2$-cells or $1 \times 10^{5}$ murine cardiomyocytes were placed in the hypoxia chamber (Billups-Rothenberg Inc., USA) flooded for $10 \mathrm{~min}$ with a nitrogen-enriched mixture of gases containing $1.5 \% \mathrm{O}_{2}$ and $5 \% \mathrm{CO}_{2}$ and incubated within this hypoxic atmosphere for $6 \mathrm{~h}$. Controls were cultured under normoxic conditions.

CMV were isolated by differential centrifugation. Approximately $8 \times 10^{5} \mathrm{CMV}$ from $\mathrm{H} 9 \mathrm{c} 2$ or $2 \times 10^{5} \mathrm{CMV}$ from murine cardiomyocytes were added to cells for stimulation experiments.

\section{Flow cytometry}

CMV from H9c2 -cells or murine cardiomyocytes were diluted in PBS and counted by flow cytometry. An MV gate was defined using Megamix-Plus Beads (BioCytex, France) to include MV with a size range between 0.2 and $1 \mu \mathrm{m}$. 10,000 counting beads (Trucount, BD, USA) were recorded per sample and the MV concentration was calculated. 
Vitality of cardiomyocytes was assessed using propidium iodide staining (PI, R\&D Systems, USA) as described previously [20].

\section{RNA extraction and qPCR}

RNA was isolated and transcribed to cDNA according to standard protocols. $\Delta \Delta \mathrm{C}_{\mathrm{t}}$ values were computed and fold change (FC) was determined as follows: fold change $=2-{ }^{\Delta \Delta \mathrm{Ct}}$.

\section{Next-generation sequencing}

RNA-samples from CMV and hypoxic H9c2 were subjected to next-generation sequencing (NGS) to detect every known as well as possible new miRNAs within these samples and NGS was performed as described previously [11].

\section{Statistics}

Differences between multiple means were assessed by one-way ANOVA. When only two columns are depicted in graphs a paired t-test was used to assess for difference of means, since treated and control samples were always handled in parallel. $\mathrm{p}<0.05$ was considered statistically significant (Asterisks: $* \mathrm{p}<0.05, * * \mathrm{p}<0.01, * * * \mathrm{p}<0.001$ ). All experiments were performed at least threefold. Analysis was performed using GraphPad Prism 8.31 and figures were prepared for submission using Adobe ${ }^{\circledR}$ Illustrator ${ }^{\circledR}$ CS6. Statistical analysis of next-generation sequencing experiments was performed as described previously [11].

\section{Results}

\section{Hypoxic H9c2-cells release MV and contain a distinct set of pro-inflammatory miRNA}

After incubation in the hypoxia chamber, CMV from H9c2cells were successfully isolated from the cell supernatant as shown by flow cytometry (Fig. 1e).

Next-generation sequencing revealed that the miRNAprofile from $\mathrm{H} 9 \mathrm{c} 2$-cells and their respective CMV differed significantly (Fig. 1f). The abundance of miRNA in cells compared to CMV was quite different as most miRNA had a higher abundance in cells than in CMV.

In the hypoxic cell samples 38 miRNA had more than 10,000 read counts and 6 more than 100,000, while in $C M V$ the highest read-count was 7,661 (miR-143) and all in all there were only 9 miRNA with a read-count greater than 1,000. The five most abundant miRNA in $C M V$ were miR10a_2, miR10b_4, miR22_1, miR143_1 and
miR423_5p). Interestingly the miRNA profile of hypoxic and non-hypoxic H9c2-cells only differed in one miRNA: miRNA-210, which is known to be upregulated during hypoxia [21]. However, miRNA-210 only showed low read counts in CMV $(<1000)$.

Several miRNA involved in inflammation or immunity were also detected in CMV and are displayed in Table 1.

\section{CMV from hypoxic H9c2-cells induce IL-6 expression in THP-1 macrophages and CRP expression in a hepatic co-culture model}

Incubation of CMV from H9c2 with THP-1 macrophages led to an increase in IL-6 expression (FC IL-6 after $48 \mathrm{~h}$, 72 h, 96 h: LPS: $59.59 \pm 10.27,196.7 \pm 37.05,47.68 \pm 7.90$ vs. CMV: $214.1 \pm 48.47,605.9 \pm 49.16,96.86 \pm 10.03$, $\mathrm{p}<0.05$; Fig. 1g-i). Increased IL-6 expression by THP-1 macrophages after CMV stimulation was verified on a protein level by an IL-6 ELISA (IL-6 [pg/mL] after 48 h, $72 \mathrm{~h}$, 96 h: LPS: $59.38 \pm 1.12,96.85 \pm 5.04,65 \pm 2.72$ vs. CMV: $171.3 \pm 14.29,193.6 \pm 11.74,240.7 \pm 18.78, \mathrm{p}<0.001$ Fig. 1j). Moreover, CMV effected a gradual increase of IL-6 and CRP expression in co-cultures over time (FC after 48 h, 72 h, 96 h: IL-6 $1.07 \pm 0.28,3.76 \pm 1.62,7.80 \pm 2.48$; CRP $1.57 \pm 0.94,3.88 \pm 2.89,13.85 \pm 5.42$, Fig. 1k). Furthermore, CRP expression in co-cultures was increased compared to the negative control (cell culture medium) after $96 \mathrm{~h}$ (FC CRP after $96 \mathrm{~h}$ : negative control 2.10 $\pm 0.82, \mathrm{CMV}$ 18.32 $\pm 3.94, \mathrm{p}<0.05$, Fig. 11).

\section{Hypoxia leads to $\mathrm{CMV}$ release from murine cardiomyocytes}

We aimed to verify the results gained from the eternal cell line H9c2 using primary murine cardiomyocytes. Isolation of murine cardiomyocytes was successful (Fig. 2a) and approx. $2.5 \times 10^{5}$ cardiomyocytes were isolated from a murine heart. Exposure of murine cardiomyocytes to hypoxia led to increased levels of troponin-T in the cell supernatant (troponin-T $[\mathrm{ng} / \mathrm{mL}]$ : hypoxia $45.95 \pm 3.88$ vs. normoxia $30.30 \pm 6.65$, p $<0.05$, Fig. 2b). Contamination of the cell culture medium by troponin-T in FBS was ruled out (troponin-T [ng/mL]: medium $0.01 \pm 0.00 \mathrm{vs}$. cell supernatant of normoxic cardiomyocytes $30.30 \pm 6.65$, $\mathrm{p}<0.05$, Fig. 2c). Hypoxia increased the percentage of dead cardiomyocytes as identified by propidium iodide PI staining (PI positive cells [\%]: normoxia 16.80 44.40 vs. hypoxia $50.87 \pm 4.50, \mathrm{p}<0.05$, Fig. 2 d). Furthermore, hypoxic cardiomyocytes released more CMV compared to their normoxic counterparts as determined by flow cytometry (CMV count x $10^{3}$ : normoxia $85.75 \pm 9.21$ vs. hypoxia $130.61 \pm 12.85, \mathrm{p}<0.01$, Fig. 2 e) 
A

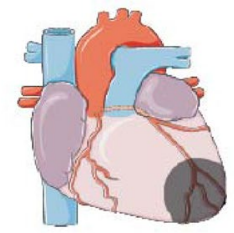

B

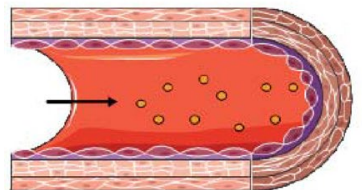

E
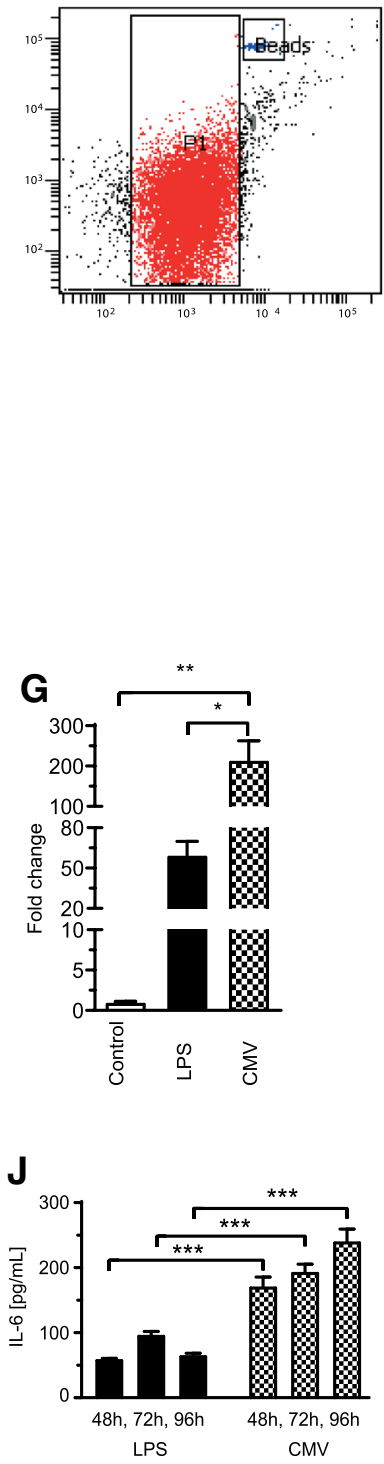

D

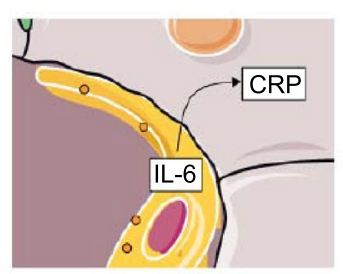

C

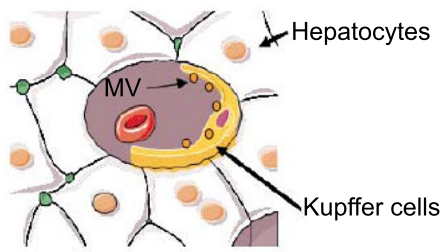

F Cardiomyocyte microvesicles Hypoxic cardiomyocytes

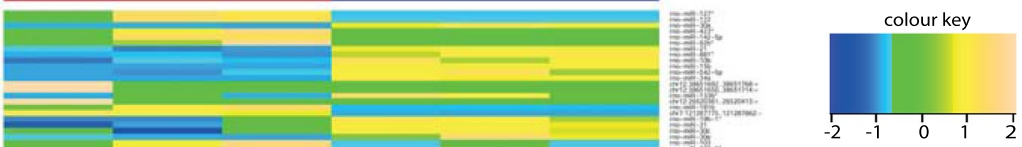

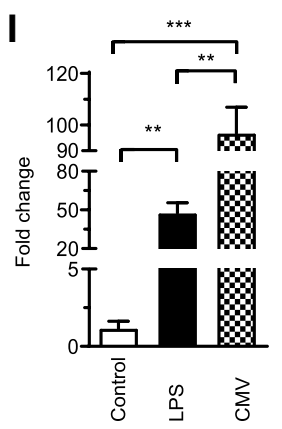

$\mathbf{L}$

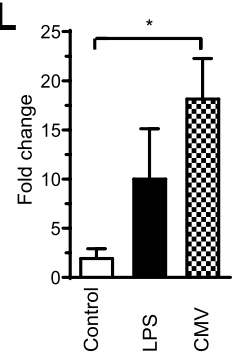


४Fig. 1 Suggested model of CMV-mediated CRP expression in hepatocytes. For more information see text, underlying images of Fig. 1a-d were adapted from http://smart.servier.com/ under a creative commons licence (a-d). Microvesicles were successfully isolated from the supernatant of hypoxic H9c2 cardiomyocytes. P1 indicates the microvesicle gate, "beads" indicates a gate for standardized counting beads (e). Next-generation sequencing revealed that CMV contain a distinct pattern of miRNA compared to their parent cells as shown by the heat map. The color key indicates the z-score of the normalised read-count of individual miRNAs. Most miRNAs had higher read counts in hypoxic cells than in CMV (f). IL-6 expression was upregulated as shown by qPCR using RNA from THP-1 macrophages after incubation with H9c2 CMV for 48 (g), 72 (h) or 96 h (i). Induction of IL- 6 expression by CMV in THP-1 macrophages was verified on a protein level by ELISA after 48, 72 and $96 \mathrm{~h}$. IL-6 levels were increased after incubation with CMV even compared to the positive control (LPS) (j). CMV induced a gradual rise in IL-6 and CRP expression in the co-culture of HepG2 and THP-1 cells as determined by qPCR $(\mathbf{k})$. CRP increase was also higher compared to the negative control exemplified after $96 \mathrm{~h}(\mathbf{l})$

\section{The miRNA profile of CMV from murine cardiomyocytes is comparable to CMV from H9C2-cells}

The most abundant miRNA in CMV from H9c2-cells were also upregulated in murine CMV compared to their parent cells indicating a similar miRNA profile (FC expression CMV vs. hypoxic cardiomyocytes: miR10a $\_2: 7.00 \pm 1.31$ vs. $1.05 \pm 0.14$, miR10b_4: $6.42 \pm 0.93$ vs. $1.09 \pm 0.20$, miR22_1: $5.70 \pm 1.44$ vs. $1.07 \pm 0.20$, miR143_1: $6.55 \pm 1.35$ vs. $1.06 \pm 0.17$, miR $423 \_5$ p: $17.64 \pm 2.90$ vs. $1.06 \pm 0.17$, $\mathrm{p}<0.01-$ p $<0.05$, Fig. 2f-j).

\section{CMV from hypoxic murine cardiomyocytes also lead to increased CRP expression in a hepatic co-culture model}

Initial experiments to assess biological capacity of CMV demonstrated that incubation of CMV with HUVEC for $18 \mathrm{~h}$ led to activation evidenced by increased ICAM-1 expression (FC expression of ICAM-1, CMV vs. negative control (PBS): $3.62 \pm 0.95$ vs. $1.12 \pm 0.26, p<0.05$, Fig. $3 a$ ). Incubation of CMV with THP-1 macrophages for $24 \mathrm{~h}$ led to an upregulation of IL-6. CRP-expression, however, was not affected by CMV after incubation with THP-1 macrophages alone (FC expression CMV vs. negative control (PBS): IL- 6: $2.91 \pm 0.51$ vs. $1.06 \pm 0.14, \mathrm{p}<0.01$, CRP: $1.01 \pm 0.46$ vs $1.02 \pm 0.05, p=0.87$; Fig. $3 b, c)$. Moreover, CMV incubation with HepG2 cells alone for up to $72 \mathrm{~h}$ did not affect IL-6 or CRP expression (FC expression CMV vs. negative control (PBS): IL-6: $0.76 \pm 0.20$ vs. $1.00 \pm 0.26$, $\mathrm{p}=0.16$, CRP: $1.19 \pm 0.42$ vs. $1.00 \pm 0.23, \mathrm{p}=0.71$, Fig. $3 \mathrm{~d}$, e). However, the incubation of CMV with a co-culture of HepG2 and THP- 1 cells for $72 \mathrm{~h}$ resulted in an increase of CRP expression compared to the negative control (FC CRP expression CMV vs. negative control (PBS): $2.40 \pm 0.72$ vs. $1.00 \pm 0.45$, p $<0.05$, Fig. 3f).

\section{Discussion}

In this study we aimed to prove our hypothesis that CMV released from hypoxic cardiomyocytes induce hepatic CRP expression. We were able to isolate CMV from both H9c2and murine cardiomyocytes after incubation in the hypoxia chamber (Figs. 1e and 2a, e). The hypoxia chamber is intended to simulate the conditions cardiomyocytes are exposed to during the ischemia after myocardial infarction and it has successfully been applied by other researchers to generate CMV [22, 23]. Increased cardiomyocyte death and rising levels of troponin- $\mathrm{T}$ are evidence that hypoxia was achieved (Fig. 2b-d).

MV can transfer miRNA between their host and target cells [24]. We therefore chose to explore the miRNA content of CMV using next-generation sequencing. It provides strong advantages over microarrays including higher sensitivity and a wider miRNA spectrum that can be analysed [25]. It revealed a changed miRNA profile in $\mathrm{H} 9 \mathrm{c} 2 \mathrm{CMV}$ compared to hypoxic H9c2-cells (Fig. 1f) which suggests a selective packaging mechanism previously described for stimulated THP-1 cells and their MV [11].

CMV from hypoxic H9c2 cardiomyocytes were rich in inflammation-affecting miRNA (Table 1). The most abundant miRNA in this group, miR-143, is increased in ischemic areas of the heart after myocardial infarction and has been shown to promote cardiac fibrosis by targeting the "Sprouty-3" gene in cardiomyocytes [26]. Moreover, increased levels of miR-143 in monocytes after myocardial infarction correlate with increased hsCRP-levels [27]. It could be hypothesized that increased uptake of CMV containing miR-143 by monocytes induces IL- 6 expression which later leads to increased CRP expression by hepatocytes.

miR-181 has been reported to alter the myocardial response to oxidative stress by targeting " $\mathrm{mt}-\mathrm{COX}-1$ " or "PTEN" [28]. miR-21 is also upregulated in the infarcted zone after myocardial infarction and promotes cardiac fibrosis by inhibition of the "Smad7" pathway [29]. The role of miR-21 in inflammation and its relation with CRP is emphasized by the fact that both elevated circulating miR-21 and increased CRP-levels after myocardial infarction are predictive of left ventricular remodelling [30]. Additionally, miR-146, which was also upregulated in CMV has been shown to increase IL-6 expression by promoting the "NFKB" pathway in an in-vitro sepsis model [31].

Little is known on the miRNA profile of CMV of mouse compared to rat cardiomyocytes. Since next-generation 
Table 1 Overview of the miRNAs known to be involved in inflammation and immunity upregulated in $\mathrm{H} 9 \mathrm{c} 2 \mathrm{CMV}$

\begin{tabular}{lcl}
\hline Name & Read count CMP & Full name \\
\hline miR-21 & 916 & mmu-miR-21-5p \\
miR-26 & 294 & mmu-miR-26a-5p \\
miR-30 & 65 & mmu-miR-30a-5p \\
miR-126 & 78 & mmu-miR-126-5p \\
miR-132 & 11 & mmu-miR-132-3p \\
miR-143 & 7661 & mmu-miR-143-3p \\
miR-146 & 53 & mmu-miR-146a-5p \\
miR-181 & 1866 & mmu-miR-181a-5p \\
\hline
\end{tabular}

sequencing was only performed for $\mathrm{H} 9 \mathrm{c} 2 \mathrm{CMV}$ we showed that the most abundant miRNAs of H9c2 CMVs were also upregulated in mouse CMV (Fig. 2f-j). As with $\mathrm{H} 9 \mathrm{c} 2 \mathrm{CMV}$, we therefore assume a distinct miRNA pattern of mouse CMV from their parent cells, murine cardiomyocytes.

To investigate the effects of CMV on the acute phase response in the liver, we successfully established a co-culture of THP-1 macrophages and HepG2 hepatocytes. This strategy is superior to monoculture of HepG2 cells since it creates a more physiologic model of the liver [32, 33]. Both, CMV from hypoxic H9c2-cells and murine CMV stimulated co-cultures to express CRP (Figs. 11 and 3f). Induction of an acute phase response in the liver by MV has also been reported by other groups, for example, by murine brain-derived microvesicles after brain injury [34].

HepG2 cells alone did not react to stimulation with CMV (Fig. 3e) with an increase in CRP production. We therefore hypothesized that there might be a paracrine mechanism via Kupffer cells. To elucidate the effects of CMV on macrophages, THP-1 macrophages alone were incubated with H9c2- or murine CMV and stimulation of IL-6 expression was found (Figs. $1 \mathrm{~g}-\mathrm{j}$ and $3 \mathrm{~b}$ ). Other groups have shown that microvesicles can induce pro-inflammatory effects on target cells $[11,35,36]$. We claim this supports our model of IL-6 production by hepatic Kupffer cells after stimulation by CMV.

Although increased levels of IL-6 have been reported after myocardial infarction [37] the major source remains unclear. Shu et al. claimed IL-6 after myocardial infarction was also produced in the vulnerable plaque and necrotic myocardium [38]. We cannot rule this out but argue it does not contradict our model since CMV may also induce IL-6 synthesis in a paracrine manner in myocardial macrophages.

Peak circulating levels of CRP after myocardial infarction correlate with infarct size, development of heart failure, and mortality $[4,39]$. This may be due to pro-inflammatory effects of CRP itself. More recently it has been found that microvesicles from patients after myocardial infarction can convert pentameric CRP into pro-inflammatory monomeric CRP [40, 41]. In light of these findings our study gains importance as it provides an explanation for the rise in CRP-levels after myocardial infarction. Moreover, it offers an opportunity to target "harmful" inflammation upstream at the beginning of the inflammatory cascade. Therapeutic options could include inhibiting CMV release after myocardial infarction using low doses of the $\mathrm{Ca}^{2+}$-Channel inhibitor Verapamil [42], inhibiting MV uptake by target cells using Annexin V [43] or by inhibiting specific miRNAs using specialized antagomirs [44].

Additionally, miRNA containing CMV may serve as novel biomarkers for the detection of myocardial infarction since they protect miRNA from degradation [45]. miRNAs which were detected in CMV in our study and have been reported as biomarkers in the literature include miR-21, miR-30 and miR-133 [46].

We would like to acknowledge the limitations of our study. The effect of cardiomyocyte MV on hepatic CRP production was not investigated in-vivo and should be confirmed in a mouse model. The exact mechanisms of how miRNA lead to increased CRP expression was not assessed and could be determined using antagomir experiments.

In summary, we demonstrated that CMV released from cardiomyocytes during hypoxia contain a distinct miRNA profile which differs from their parent cells. Furthermore, 


\section{A}

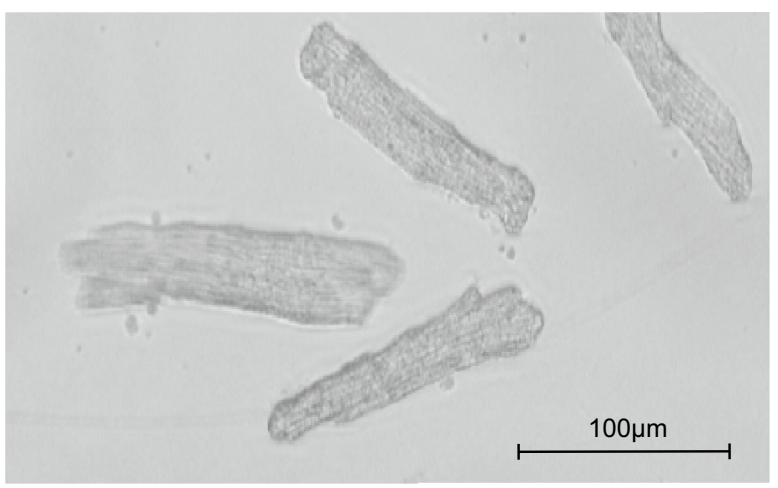

B

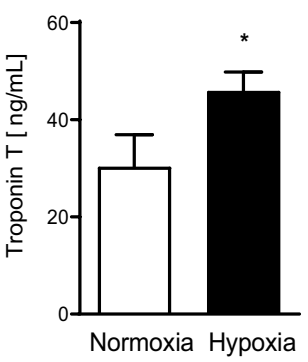

$F$

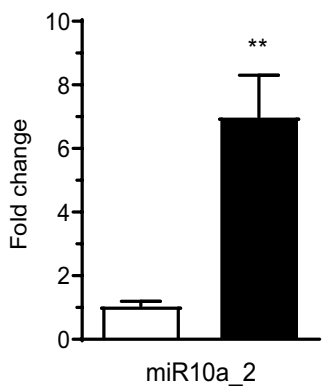

C

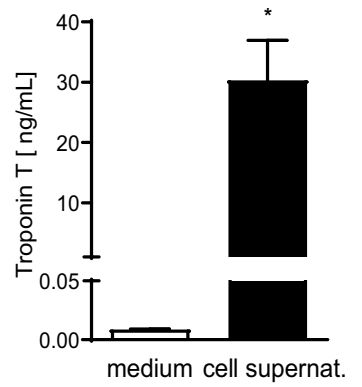

D

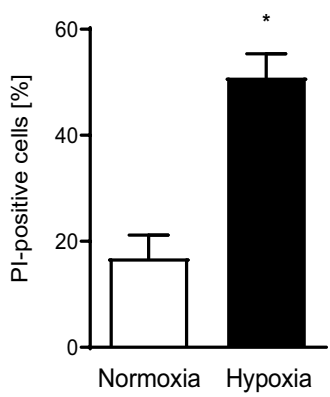

E

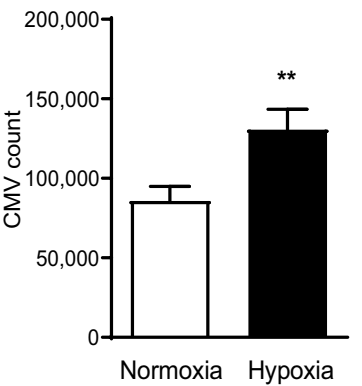

Fig. 2 Murine cardiomyocytes were successfully isolated and cultivated from whole murine hearts visualized by light transmission microscopy (a). Increased levels of troponin-T were recorded in the supernatant of cardiomyocytes exposed to hypoxia (b). Contamination of cell culture medium with troponin-T was ruled out (c). Exposure to hypoxia led to significantly increased cardiomyocyte death compared to normoxic conditions as shown by PI staining in
G

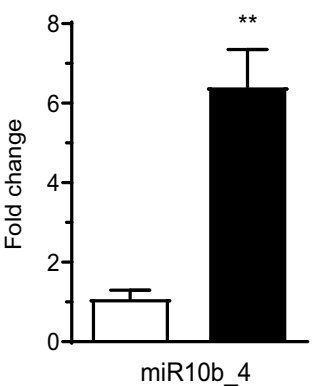

H

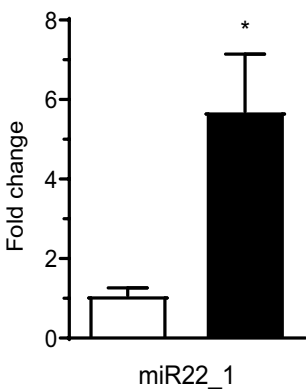

I

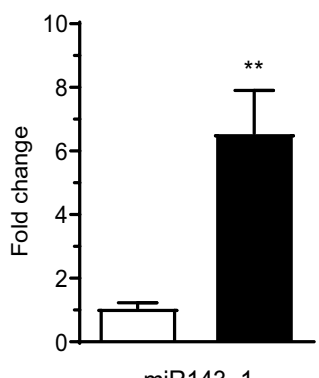

J $\square$ Cardiomyocytes

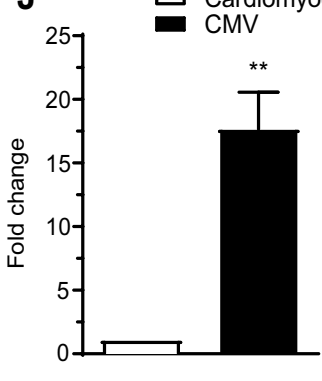

flow cytometry (d). More CMV were released from murine cardiomyocytes under hypoxic conditions and counted by flow cytometry (e). Murine CMV displayed a similar miRNA profile as H9c2 CMV. qPCR showed that the 5 most abundant miRNA in H9c2 CMV were also upregulated in murine CMV (black columns) compared to cardiomyocytes (white columns) (f-j) 
A

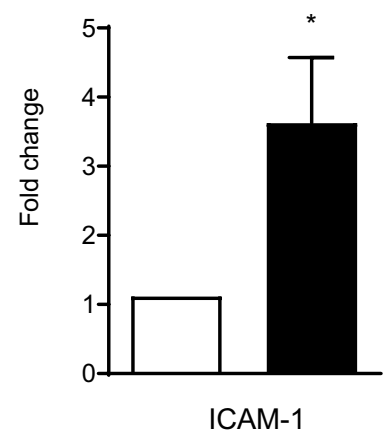

D

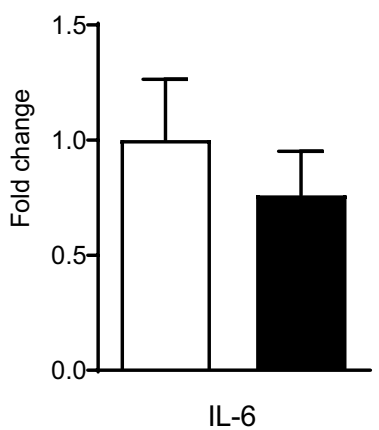

B

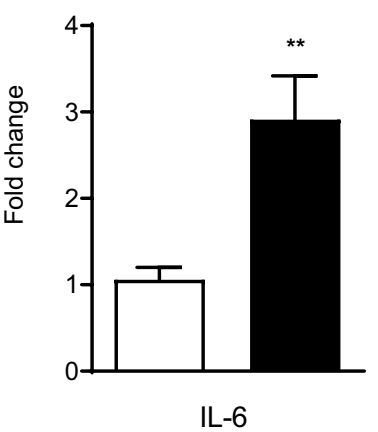

E

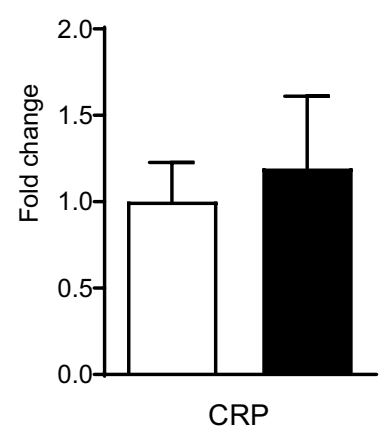

C

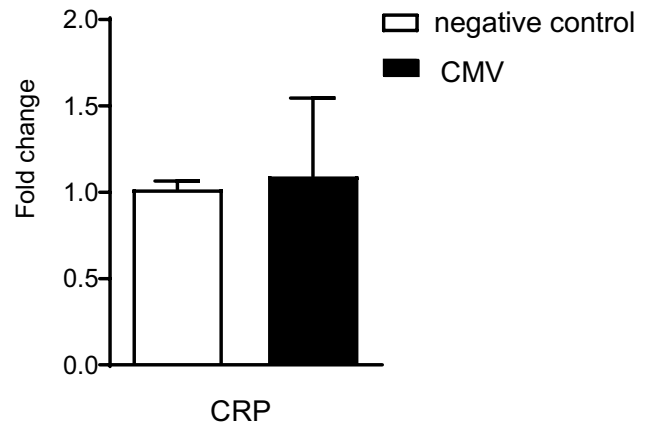

$\mathbf{F}$

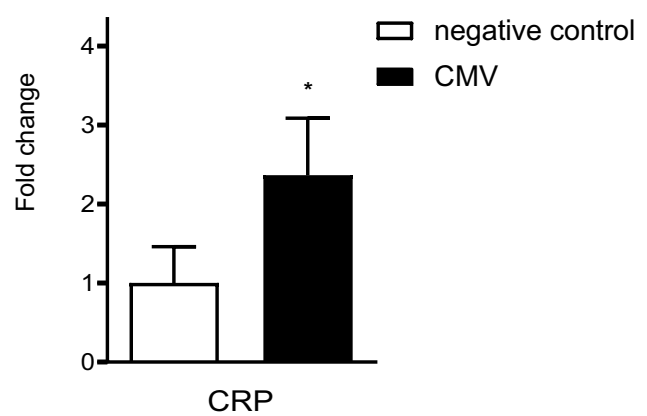

Fig. 3 Biological capacity of murine CMV was first assessed on HUVEC. Increased ICAM-1 expression was shown by qPCR after incubation of CMV with HUVEC (a). Murine CMV induced upregulation of IL-6 in a monoculture of THP-1 macrophages (b) but did not affect CRP expression in these cells alone (c) as shown by qPCR.

CMV were able to induce CRP expression in a liver coculture model of HepG2 and THP-1 cells.

Funding This work was supported by the German Research Foundation (DFG) and by the National Health and Medical Research Council (NHMRC) of Australia. Open Access funding enabled and organized by Projekt DEAL.

Availability of data and material All data is available from the authors upon reasonable request.

Code availability Not applicable.

\section{Compliance with ethical standards}

Conflict of interest The authors declare no conflicts of interest.

Ethical approval All animal studies were approved by the ethics committee of the University of Freiburg Medical Center (Ethics No. $\mathrm{X} 17 / 02 \mathrm{R})$.

Informed consent Not applicable.

Consent for publication Not applicable.
Incubation of CMV with a monoculture of HepG2 cells did not affect either IL- 6 or CRP expression determined by qPCR (d, e). However, in a co-culture of HepG2 hepatocytes and THP-1 macrophages CRP expression was elevated by CMV as determined by qPCR (f)

Open Access This article is licensed under a Creative Commons Attribution 4.0 International License, which permits use, sharing, adaptation, distribution and reproduction in any medium or format, as longas you give appropriate credit to the original author(s) and the source,provide a link to the Creative Commons licence, and indicate if changeswere made. The images or other third party material in this article areincluded in the article's Creative Commons licence, unless indicatedotherwise in a credit line to the material. If material is not included inthe article's Creative Commons licence and your intended use is notpermitted by statutory regulation or exceeds the permitted use, you willneed to obtain permission directly from the copyright holder. To view acopy of this licence, visit http://creativecommons. org/licenses/by/4.0/.

\section{References}

1. Benjamin EJ, Muntner P, Alonso A, Bittencourt MS, Callaway CW, Carson AP, Chamberlain AM, Chang AR, Cheng S, Das SR, Delling FN, Djousse L, Elkind MSV, Ferguson JF, Fornage M, Jordan LC, Khan SS, Kissela BM, Knutson KL, Kwan TW, Lackland DT, Lewis TT, Lichtman JH, Longenecker CT, Loop MS, Lutsey PL, Martin SS, Matsushita K, Moran AE, Mussolino ME, O'Flaherty M, Pandey A, Perak AM, Rosamond WD, Roth GA, Sampson UKA, Satou GM, Schroeder EB, Shah SH, Spartano NL, Stokes A, Tirschwell DL, Tsao CW, Turakhia MP, VanWagner 
LB, Wilkins JT, Wong SS, Virani SS (2019) Heart disease and stroke statistics-2019 update: a report from the American Heart Association. Circulation 139(10):e56-e528. https://doi.org/10. 1161/cir.0000000000000659

2. Granger CB, Kochar A (2018) Understanding and targeting inflammation in acute myocardial infarction. An elusive goal. J Am Coll Cardiol 72(2):199-201. https://doi.org/10.1016/j.jacc. 2018.05.006

3. Bursi F, Weston SA, Killian JM, Gabriel SE, Jacobsen SJ, Roger VL (2007) C-reactive protein and heart failure after myocardial infarction in the community. Am J Med 120(7):616-622. https:// doi.org/10.1016/j.amjmed.2006.07.039

4. Suleiman M, Khatib R, Agmon Y, Mahamid R, Boulos M, Kapeliovich M, Levy Y, Beyar R, Markiewicz W, Hammerman H, Aronson D (2006) Early inflammation and risk of long-term development of heart failure and mortality in survivors of acute myocardial infarction predictive role of C-reactive protein. $\mathrm{J}$ Am Coll Cardiol 47(5):962-968. https://doi.org/10.1016/j.jacc. 2005.10.055

5. Volanakis JE (2001) Human C-reactive protein: expression, structure, and function. Mol Immunol 38(2-3):189-197. https:// doi.org/10.1016/s0161-5890(01)00042-6

6. Thompson D, Pepys MB, Wood SP (1999) The physiological structure of human C-reactive protein and its complex with phosphocholine. Structure 7(2):169-177. https://doi.org/10.1016/ s0969-2126(99)80023-9

7. Black S, Kushner I, Samols D (2004) C-reactive protein. J Biol Chem 279(47):48487-48490. https://doi.org/10.1074/jbc.R4000 25200

8. Sturk A, Hack CE, Aarden LA, Brouwer M, Koster RR, Sanders GT (1992) Interleukin-6 release and the acute-phase reaction in patients with acute myocardial infarction: a pilot study. J Lab Clin Med 119(5):574-579

9. Marcoux G, Duchez AC, Cloutier N, Provost P, Nigrovic PA, Boilard E (2016) Revealing the diversity of extracellular vesicles using high-dimensional flow cytometry analyses. Sci Rep 6:35928. https://doi.org/10.1038/srep35928

10. Yu H, Wang Z (2019) Cardiomyocyte-derived exosomes: biological functions and potential therapeutic implications. Front Physiol 10:1049-1049. https://doi.org/10.3389/fphys.2019. 01049

11. Diehl P, Fricke A, Sander L, Stamm J, Bassler N, Htun N, Ziemann M, Helbing T, El-Osta A, Jowett JB, Peter K (2012) Microparticles: major transport vehicles for distinct microRNAs in circulation. Cardiovasc Res 93(4):633-644. https://doi.org/ $10.1093 / \mathrm{cvr} / \mathrm{cvs} 007$

12. Loyer X, Zlatanova I, Devue C, Yin M, Howangyin K-Y, Klaihmon P, Guerin CL, Kheloufi M, Vilar J, Zannis K, Fleischmann BK, Hwang DW, Park J, Lee H, Menasché P, Silvestre J-S, Boulanger CM (2018) Intra-cardiac release of extracellular vesicles shapes inflammation following myocardial infarction. Circ Res 123(1):100-106. https://doi.org/10.1161/CIRCRESAHA.117. 311326

13. Yang J, Yu X, Xue F, Li Y, Liu W, Zhang S (2018) Exosomes derived from cardiomyocytes promote cardiac fibrosis via myocyte-fibroblast cross-talk. Am J Transl Res 10(12):4350-4366

14. Yu X, Deng L, Wang D, Li N, Chen X, Cheng X, Yuan J, Gao X, Liao M, Wang M, Liao Y (2012) Mechanism of TNF-alpha autocrine effects in hypoxic cardiomyocytes: initiated by hypoxia inducible factor 1alpha, presented by exosomes. J Mol Cell Cardiol 53(6):848-857. https://doi.org/10.1016/j.yjmcc.2012.10.002

15. Waldenström A, Gennebäck N, Hellman U, Ronquist G (2012) Cardiomyocyte microvesicles contain DNA/RNA and convey biological messages to target cells. PLoS ONE 7(4):e34653. https:// doi.org/10.1371/journal.pone.0034653
16. Chaturvedi P, Kalani A, Medina I, Familtseva A, Tyagi SC (2015) Cardiosome mediated regulation of MMP9 in diabetic heart: role of mir29b and mir455 in exercise. J Cell Mol Med 19(9):21532161. https://doi.org/10.1111/jcmm.12589

17. Giricz Z, Varga ZV, Baranyai T, Sipos P, Pálóczi K, Kittel Á, Buzás EI, Ferdinandy P (2014) Cardioprotection by remote ischemic preconditioning of the rat heart is mediated by extracellular vesicles. J Mol Cell Cardiol 68:75-78. https://doi.org/10. 1016/j.yjmcc.2014.01.004

18. Zordoky BN, El-Kadi AO (2007) H9c2 cell line is a valuable in vitro model to study the drug metabolizing enzymes in the heart. J Pharmacol Toxicol Methods 56(3):317-322. https://doi. org/10.1016/j.vascn.2007.06.001

19. O'Connell TD, Rodrigo MC, Simpson PC (2007) Isolation and culture of adult mouse cardiac myocytes. Methods Mol Biol 357:271-296. https://doi.org/10.1385/1-59745-214-9:271

20. Riccardi C, Nicoletti I (2006) Analysis of apoptosis by propidium iodide staining and flow cytometry. Nat Protoc 1(3):1458-1461. https://doi.org/10.1038/nprot.2006.238

21. Camps C, Buffa FM, Colella S, Moore J, Sotiriou C, Sheldon H, Harris AL, Gleadle JM, Ragoussis J (2008) hsa-miR-210 Is induced by hypoxia and is an independent prognostic factor in breast cancer. Clin Cancer Res 14(5):1340-1348. https://doi.org/ 10.1158/1078-0432.ccr-07-1755

22. Yu X, Deng L, Wang D, Li N, Chen X, Cheng X, Yuan J, Gao X, Liao M, Wang M, Liao Y (2012) Mechanism of TNF- $\alpha$ autocrine effects in hypoxic cardiomyocytes: Initiated by hypoxia inducible factor $1 \alpha$, presented by exosomes. J Mol Cell Cardiol 53(6):848857. https://doi.org/10.1016/j.yjmcc.2012.10.002

23. Gupta S, Knowlton AA (2007) HSP60 trafficking in adult cardiac myocytes: role of the exosomal pathway. Am J Physiol Heart Circ Physiol 292(6):H3052-H3056. https://doi.org/10.1152/ajpheart. 01355.2006

24. Valadi H, Ekstrom K, Bossios A, Sjostrand M, Lee JJ, Lotvall JO (2007) Exosome-mediated transfer of mRNAs and microRNAs is a novel mechanism of genetic exchange between cells. Nat Cell Biol 9(6):654-659. https://doi.org/10.1038/ncb1596

25. Zhang J, Chiodini R, Badr A, Zhang G (2011) The impact of next-generation sequencing on genomics. J Genet Genomics 38(3):95-109. https://doi.org/10.1016/j.jgg.2011.02.003

26. Li C, Li J, Xue K, Zhang J, Wang C, Zhang Q, Chen X, Gao C, Yu X, Sun L (2019) MicroRNA-143-3p promotes human cardiac fibrosis via targeting sprouty3 after myocardial infarction. J Mol Cell Cardiol 129:281-292. https://doi.org/10.1016/j.yjmcc.2019. 03.005

27. Parahuleva MS, Euler G, Mardini A, Parviz B, Schieffer B, Schulz $\mathrm{R}$, Aslam M (2017) Identification of microRNAs as potential cellular monocytic biomarkers in the early phase of myocardial infarction: a pilot study. Sci Rep 7(1):15974. https://doi.org/10. 1038/s41598-017-16263-y

28. Das S, Kohr M, Dunkerly-Eyring B, Lee DI, Bedja D, Kent OA, Leung AK, Henao-Mejia J, Flavell RA, Steenbergen C (2017) Divergent effects of miR-181 family members on myocardial function through protective cytosolic and detrimental mitochondrial microRNA targets. J Am Heart Assoc. https://doi.org/10.1161/ jaha.116.004694

29. Yuan J, Chen H, Ge D, Xu Y, Xu H, Yang Y, Gu M, Zhou Y, Zhu J, Ge T, Chen Q, Gao Y, Wang Y, Li X, Zhao Y (2017) Mir-21 promotes cardiac fibrosis after myocardial infarction via targeting Smad7. Cell Physiol Biochem 42(6):2207-2219. https://doi.org/ 10.1159/000479995

30. Liu X, Dong Y, Chen S, Zhang G, Zhang M, Gong Y, Li X (2015) Circulating MicroRNA-146a and MicroRNA-21 predict left ventricular remodeling after ST-elevation myocardial infarction. Cardiology 132(4):233-241. https://doi.org/10.1159/000437090 
31. Pfeiffer D, Roßmanith E, Lang I, Falkenhagen D (2017) miR146a, miR-146b, and miR-155 increase expression of IL-6 and IL-8 and support HSP10 in an In vitro sepsis model. PLoS ONE 12(6):e0179850-e0179850. https://doi.org/10.1371/journal.pone. 0179850

32. Tukov FF, Maddox JF, Amacher DE, Bobrowski WF, Roth RA, Ganey PE (2006) Modeling inflammation-drug interactions in vitro: a rat Kupffer cell-hepatocyte coculture system. Toxicol In Vitro 20(8):1488-1499. https://doi.org/10.1016/j.tiv.2006.04. 005

33. Matak P, Chaston TB, Chung B, Srai SK, McKie AT, Sharp PA (2009) Activated macrophages induce hepcidin expression in HuH7 hepatoma cells. Haematologica 94(6):773-780. https:// doi.org/10.3324/haematol.2008.003400

34. Couch Y, Evans MC, Gardiner C, Sargent I, Losey P, Lambertsen KL, Anthony DC (2014) Brain-derived microvesicles confer sickness behaviours by switching on the acute phase response in the liver. J Neuroimmunol 275(1):57. https://doi.org/10.1016/j.jneur oim.2014.08.150

35. Neri T, Armani C, Pegoli A, Cordazzo C, Carmazzi Y, Brunelleschi S, Bardelli C, Breschi MC, Paggiaro P, Celi A (2011) Role of NF-kappaB and PPAR-gamma in lung inflammation induced by monocyte-derived microparticles. Eur Respir J 37(6):1494-1502. https://doi.org/10.1183/09031936.00023310

36. Fink K, Moebes M, Vetter C, Bourgeois N, Schmid B, Bode C, Helbing T, Busch H-J (2015) Selenium prevents microparticleinduced endothelial inflammation in patients after cardiopulmonary resuscitation. Crit Care 19(1):58-58. https://doi.org/10.1186/ s13054-015-0774-3

37. Ikeda U, Ohkawa F, Seino Y, Yamamoto K, Hidaka Y, Kasahara T, Kawai T, Shimada K (1992) Serum interleukin 6 levels become elevated in acute myocardial infarction. J Mol Cell Cardiol 24(6):579-584. https://doi.org/10.1016/0022-2828(92)91042-4

38. Shu J, Ren N, Du JB, Zhang M, Cong HL, Huang TG (2007) Increased levels of interleukin-6 and matrix metalloproteinase-9 are of cardiac origin in acute coronary syndrome. Scand Cardiovasc J 41(3):149-154. https://doi.org/10.1080/140174306011642 63

39. Suleiman M, Aronson D, Reisner SA, Kapeliovich MR, Markiewicz W, Levy Y, Hammerman H (2003) Admission C-reactive protein levels and 30-day mortality in patients with acute myocardial infarction. Am J Med 115(9):695-701. https://doi.org/10. 1016/j.amjmed.2003.06.008
40. Thiele JR, Habersberger J, Braig D, Schmidt Y, Goerendt K, Maurer V, Bannasch H, Scheichl A, Woollard KJ, von Dobschutz E, Kolodgie F, Virmani R, Stark GB, Peter K, Eisenhardt SU (2014) Dissociation of pentameric to monomeric C-reactive protein localizes and aggravates inflammation: in vivo proof of a powerful proinflammatory mechanism and a new anti-inflammatory strategy. Circulation 130(1):35-50. https://doi.org/10.1161/circulationaha. 113.007124

41. Habersberger J, Strang F, Scheichl A, Htun N, Bassler N, Merivirta RM, Diehl P, Krippner G, Meikle P, Eisenhardt SU, Meredith I, Peter K (2012) Circulating microparticles generate and transport monomeric C-reactive protein in patients with myocardial infarction. Cardiovasc Res 96(1):64-72. https://doi.org/10. $1093 / \mathrm{cvr} / \mathrm{cvs} 237$

42. Cordazzo C, Petrini S, Neri T, Lombardi S, Carmazzi Y, Pedrinelli R, Paggiaro P, Celi A (2014) Rapid shedding of proinflammatory microparticles by human mononuclear cells exposed to cigarette smoke is dependent on $\mathrm{Ca} 2+$ mobilization. Inflamm Res 63(7):539-547. https://doi.org/10.1007/s00011-014-0723-7

43. Terrisse AD, Puech N, Allart S, Gourdy P, Xuereb JM, Payrastre B, Sie P (2010) Internalization of microparticles by endothelial cells promotes platelet/endothelial cell interaction under flow. $\mathrm{J}$ Thromb Haemost 8(12):2810-2819. https://doi.org/10.1111/j. 1538-7836.2010.04088.x

44. Christopher AF, Kaur RP, Kaur G, Kaur A, Gupta V, Bansal P (2016) MicroRNA therapeutics: discovering novel targets and developing specific therapy. Perspect Clin Res 7(2):68-74. https:// doi.org/10.4103/2229-3485.179431

45. Cheng L, Sharples RA, Scicluna BJ, Hill AF (2014) Exosomes provide a protective and enriched source of miRNA for biomarker profiling compared to intracellular and cell-free blood. J Extracell Ves 3(1):23743. https://doi.org/10.3402/jev.v3.23743

46. Kaur A, Mackin ST, Schlosser K, Wong FL, Elharram M, Delles C, Stewart DJ, Dayan N, Landry T, Pilote L (2019) Systematic review of microRNA biomarkers in acute coronary syndrome and stable coronary artery disease. Cardiovasc Res. https://doi.org/10. 1093/cvr/cvz302

Publisher's Note Springer Nature remains neutral with regard to jurisdictional claims in published maps and institutional affiliations. 